\title{
Acción protectora de la melatonina sobre células mononucleares de sangre periférica humana sometidas a radiación gamma $\mathrm{Co}^{60}$
}

\author{
Martha Mesa-Villanueva ${ }^{1 *}$, Magaly Rueda-Martínez ${ }^{1}$, Ruby Zayas-Camacho ${ }^{1}$, \\ Diana Sicard-Suárez ${ }^{2}$, Helena Groot de Restrepo ${ }^{2}$ \\ ${ }^{1}$ Departamento de Microbiología, Facultad de Ciencias, Pontificia Universidad Javeriana, Cra. 7 No 43-82, Bogotá, Colombia \\ ${ }^{2}$ Departamento de Ciencias Biológicas, Universidad de Los Andes \\ Cra. 1 No.18A-10. Edificio M1, piso 2. Bogotá, Colombia \\ *mmesa@javeriana.edu.co
}

Recibido: 05-11-2008; Aceptado: 27-03-2009

\begin{abstract}
Resumen
Objetivo: Evaluar el efecto protector de la melatonina sobre células mononucleares de sangre periférica (CMSP) humana expuestas in vitro a radiación ionizante. Materiales y métodos: Las CMSP de donantes sanos fueron incubadas con melatonina en concentraciones de 0 , $1 \times 10^{-5}, 1 \times 10^{-6}$ y $1 \times 10^{-7} \mathrm{M}$ durante 10 minutos antes de ser expuestas a rayos gamma (300cGy, fuente de $\mathrm{Co}^{60}$ ); posteriormente el daño del ADN fue evaluado mediante el Ensayo del Cometa. Resultados: Las CMSP pre-tratadas con melatonina presentaron cometas con colas de menor longitud que las no tratadas así como un porcentaje menor de células con daño severo del DNA. Conclusión: Concentraciones de melatonina de $1 \times 10^{-5}, 1 \times 10^{-6}$ y $1 \times 10^{-7} \mathrm{M}$ protegen in vitro a las CMSP del daño en el ADN (rupturas de cadena sencilla y sitios lábiles al álcali) inducido por rayos gamma.
\end{abstract}

Palabras clave: células mononucleares sanguíneas, daño en el ADN, ensayo del cometa, melatonina, radiación gamma.

\begin{abstract}
Protective action of melatonin on human peripheral blood mononuclear cells exposed to gamma radiation $\mathrm{Co}^{60}$. Objective: to evaluate the protective effect of melatonin on peripheral blood mononuclear cells (PBMCs) exposed in vitro to ionizing radiation. Materials and methods: PBMCs drawn from healthy volunteers were incubated with $0,1 \times 10^{-5}, 1 \times 10^{-6}$ y $1 \times 10^{-7} \mathrm{M}$ melatonin for 10 minutes before being exposed to gamma radiation (300 cGy; $\mathrm{Co}^{60}$ source). Afterwards, DNA damage was evaluated with the comet assay. Results: PBMCs pretreated with melatonin showed comet tails shorter than those without the hormone treatment, as well as a lower percentage of cells with severe DNA damage. Conclusion: melatonin doses of $1 \times 10^{-5}, 1 \times 10^{-6}$ and $1 \times 10^{-7} \mathrm{M}$ provide in vitro protection to PBMCs from DNA damage (single strand breaks and alkali-labile sites) induced by gamma radiation ( $300 \mathrm{cGy} ; \mathrm{Co}^{60}$ source).
\end{abstract}

Key words: blood mononuclear cells, comet assay, DNA damage, gamma radiation, melatonin.

\section{Resumo}

Ação protetora da melatonina nas células mononucleares do sangue periférico humano submetido à radiação gama co ${ }^{60}$. Objetivo: Avaliar o efeito protetor da melatonina sobre células mononucleares do sangue periférico (CMSP) humano, expostas in vitro à radiação ionizante. Materiais e Métodos: As CMSP de pessoas sadias foram incubadas com melatonina em concentrações de $0,1 \times 10^{-5}$, $1 \times 10^{-6}$ y $1 \times 10^{-7} \mathrm{M}$ durante 10 minutos antes de serem expostas a raios gama (300cGy, fonte de $\mathrm{Co}^{60}$ ); posteriormente, o dano do DNA foi avaliado mediante o Teste do Cometa. Resultados: As CMSP previamente tratadas com melatonina apresentaram cometas com caudas de menor comprimento que as não tratadas, assim como uma porcentagem menor de células com dano severo do DNA. Conclusões: Concentrações de melatonina de $1 \times 10^{-5}, 1 \times 10^{-6}$ e $1 \times 10^{-7} \mathrm{M}$ protegem in vitro as CMPS do dano no DNA (rupturas de cadeia simples e sítios débeis ao álcali) induzido pelos raios gama.

Palavras chave: células mononucleares sangüíneas, dano no DNA, teste do cometa, melatonina, radiação gama. 


\section{Introducción}

Las radiaciones son ondulaciones o emisiones de energía procedentes de un centro o fuente que se propagan en el espacio en forma similar a la luz. Se consideran ionizantes cuando su energía es suficiente para expulsar electrones de los orbitales de átomos o moléculas (rayos X, rayos gamma). Cuando un tejido vivo se expone a estas radiaciones ya sea accidentalmente o con fines terapéuticos hay liberación localizada de gran cantidad de energía que afecta no sólo el tejido blanco sino también el tejido circundante. Los efectos deletéreos de la radiación sobre las células se deben a mecanismos directos e indirectos. Los directos se relacionan con ruptura de moléculas sensibles como el ADN y los indirectos se deben a la reacción de las radiaciones con moléculas de agua que genera radicales libres altamente reactivos como el $\cdot \mathrm{OH}$ y el $\cdot \mathrm{H}$; éstos difunden al azar y aunque tienen una vida media muy corta oxidan rápidamente proteínas, polisacáridos, lípidos y ácidos nucleicos causando daño o muerte celular (1-3). El ADN es el blanco celular más crítico y el radical $\cdot \mathrm{OH}$ el responsable del $70 \%$ de su daño. Entre las lesiones que ocasiona la radiación ionizante se encuentran formación de sitios abásicos, rupturas de cadena sencilla y de cadena doble, aductos intracatenarios y entrecruzamiento de proteínas con ADN. Si los mecanismos de reparación del ADN que se activan luego de exposición a radiación ionizante son insuficientes para reparar la lesión, el ADN dañado que se replica puede conducir a mutagénesis y carcinogénesis (4).

Para evitar el daño oxidante y proteger a la célula del efecto nocivo de los radicales libres, se han estudiado moléculas con capacidad antioxidante de tipo sintético como la amifostina (5) y de tipo natural como las vitaminas A y E, la melatonina, el manitol y el glutatión (GSH). La melatonina, el principal producto de la glándula pineal del hombre (6-8) es conocida por su capacidad de interactuar directamente con los radicales $\cdot \mathrm{OH}$; primero forma un radical melatonino de muy baja toxicidad que posteriormente puede remover un segundo radical $\cdot \mathrm{OH}$ formando 3-hidroximelatonina cíclica. Mediante este mecanismo no enzimático, la célula es protegida por la melatonina frente a los radicales libres y a las especies reactivas de oxígeno; de esta forma se evita que estas moléculas pierdan electrones, se inestabilicen y dañen moléculas como el ADN (5, 9-11).

Con el fin de conocer el efecto protector de la melatonina sobre el daño del ADN causado por radiaciones se creó un modelo de estudio a partir de células mononucleares obtenidas de sangre periférica (CMSP) humana, que se expusieron a radiación gamma en presencia y ausencia de esta hormona. El daño en el ADN antes y después de los diferentes tratamientos fue evaluado con el ensayo del cometa. Esta prueba desarrollada por Östling y Johansson en 1984 consiste en una electroforesis de ADN de células individuales en microplaca de agarosa. El ADN que ha sufrido rupturas migra desde el núcleo de la célula hasta el ánodo en forma semejante a un cometa que puede ser visualizado en el microscopio con tinción de bromuro de etidio. Esta técnica ha sido utilizada para evaluar la genotoxicidad de agentes químicos o físicos (12) y puede emplearse para estudiar el efecto de compuestos potencialmente protectores (13).

La prueba del cometa es rápida, sencilla y sensible para detectar rupturas de ADN en células individuales, y permite el estudio del daño y la reparación del ADN. El ensayo puede realizarse a diferentes pHs. La versión alcalina es utilizada para determinar rupturas de cadena sencilla, sitios lábiles al álcali y entrecruzamientos de $\mathrm{ADN}-\mathrm{ADN}$ y ADN-proteínas (12).

\section{Materiales y métodos}

\section{Separación de CMSP}

Se realizó a partir de sangre periférica de 3-4 donantes voluntarios sanos (edad $=20-25$ años) recolectada con heparina. Las CMSP se obtuvieron mediante centrifugación en gradiente de densidad de Ficoll-Hypaque (Sigma, H8889 d=1,077) y se resuspendieron en solución salina tamponada con fosfatos (PBS, $\mathrm{pH}=7,4$ ) a una concentración final de 2’500.000 células $/ \mathrm{ml}$.

\section{Preparación de soluciones de melatonina}

Se preparó una solución concentrada de melatonina $1 \times 10^{-1}$ $\mathrm{M}$ en etanol absoluto y a partir de ésta, se prepararon soluciones $1 \times 10^{-5}, 1 \times 10^{-6}$ y $1 \times 10^{-7} \mathrm{M}$ en PBS.

\section{Tratamiento de CMSP con radiación y melatonina}

Las CMSP se sometieron a radiación gamma (300cGy) en un acelerador de partículas de Cobalto ${ }^{60}$ (Terady, Instituto Nacional de Cancerología, Bogotá). Para facilitar el procedimiento, las células se suspendieron en $1 \mathrm{ml}$ de PBS en jeringas de insulina para que en el momento de la radiación no existieran espacios vacíos que causaran alteraciones en la dosis de rayos gamma. Las diferentes concentraciones de melatonina se adicionaron a las células 10 minutos antes de la irradiación. Al finalizar los tratamientos, las células fueron mantenidas en frío antes de realizar el ensayo del cometa, para evitar la acción de los mecanismos de reparación del ADN. Los tratamientos realizados 
fueron los siguientes: $i)$ Células control (sin melatonina y sin radiación gamma $\left(\mathrm{Co}^{60}\right)$; ii) Células $+300 \mathrm{cGy}\left(\mathrm{Co}^{60}\right)$; iii) Células + Melatonina $1 \times 10^{-5} \mathrm{M}+300 \mathrm{cGy}\left(\mathrm{Co}^{60}\right)$; iv) Células + Melatonina $\left.1 \times 10^{-6} \mathrm{M}+300 \mathrm{cGy}\left(\mathrm{Co}^{60}\right) ; v\right)$ Células + Melatonina $1 \times 10^{-7} \mathrm{M}+300 \mathrm{cGy}\left(\mathrm{Co}^{60}\right)$; vi) Células + Melatonina $1 \times 10^{-5} \mathrm{M}$; vii) Células + Melatonina $1 \times 10^{-6}$ $\mathrm{M}$; viii) Células + Melatonina $1 \times 10^{-7} \mathrm{M}$.

\section{Evaluación del daño del ADN mediante el ensayo del cometa}

Preparación de láminas base con agarosa: se preparó agarosa de punto de fusión normal (A-9539 Sigma, San José, CA.) en PBS libre de $\mathrm{Ca}^{++}$y $\mathrm{Mg}^{++}$al $1 \%$. En la agarosa todavía líquida se sumergieron láminas portaobjeto para crear una película delgada y uniforme. Las láminas se almacenaron a temperatura ambiente hasta el montaje de la suspensión celular. Montaje de la suspensión celular en lámina: las suspensiones celulares fueron centrifugadas y resuspendidas en $200 \mu \mathrm{l}$ de PBS. Diez $\mu \mathrm{l}$ de esta suspensión celular se mezclaron con $70 \mu \mathrm{l}$ de agarosa de bajo punto de fusión (Sigma, A-9414) al 0,5\%. Cada mezcla se depositó rápidamente sobre una lámina base, se cubrió con laminilla cubreobjeto y se dejó a $4^{\circ} \mathrm{C}$ durante 15 minutos Después de la gelificación se agregó otra capa $100 \mathrm{ml}$ de agarosa de bajo punto de fusión y se incubaron las láminas nuevamente a $4^{\circ} \mathrm{C}$ durante 15 minutos Inmediatamente después, las láminas fueron sumergidas en solución de lisis $(\mathrm{NaCl} 2.5 \mathrm{M}$, EDTA 100 mM, Tris 10 mM, NaOH 300 mM, Lauryl Sarcosinato de Sodio 1\%, pH=10), estéril y filtrada. La solución de trabajo contenía además triton X-100 1\% y dimetil sulfóxido $10 \%$ y fue refrigerada por un periodo máximo de 48 horas.

Electroforesis alcalina: este procedimiento se realizó en cuarto oscuro para evitar daño adicional por luz blanca. Las láminas se retiraron de la solución de lisis y se lavaron con agua destilada. Luego se colocaron en la cámara de electroforesis horizontal a $4^{\circ} \mathrm{C}$, se cubrieron con tampón de electroforesis ( $\mathrm{NaOH} 10 \mathrm{~N}$, EDTA $200 \mathrm{mM}, \mathrm{pH}=13)$ y se dejaron en reposo 30 minutos. Al cabo de este tiempo, se realizó la electroforesis a $25 \mathrm{~V}$ y $300 \mathrm{~mA}$ por 20 minutos. Terminada la electroforesis, se lavaron las láminas con solución neutralizante (4,85\% de Trizma Base/Sigma T-1503; ajustando el $\mathrm{pH}=7.5$ con $\mathrm{HCl}$ ) y se conservaron en cámara húmeda hasta el momento de su tinción.

Coloración y lectura: para visualizar el ADN se adicionaron $50 \mu \mathrm{l}$ de bromuro de etidio ( $0.002 \%$ en agua destilada) a cada lámina y se cubrieron con laminilla para la lectura en un microscopio Zeiss de fluorescencia con un filtro de 515-660 nm. En cada experimento se prepararon tres láminas y en cada lámina se observaron 25 células para un total de 75 células por tratamiento. El daño en el ADN se determinó midiendo con un micrómetro la longitud del cometa desde el centro del núcleo de la célula hasta el último punto observable de ADN fluorescente. También se elaboró una escala de daño de acuerdo con la longitud del cometa de la siguiente forma: Daño 1 (espontáneo) menor o igual a $57 \mu \mathrm{m}$; daño 2: 58-114 $\mu \mathrm{m}$; daño 3: 115-228 $\mu \mathrm{m}$; daño 4: mayor de $228 \mu \mathrm{m}$.

\section{Análisis de datos}

Se realizaron análisis de diferencias entre 2 grupos mediante la prueba de Mann-Whitney en el programa GraphPad Prism versión 5.0, para Windows, GraphPad Software (San Diego CA). La significancia estadística se estableció para valores $\mathrm{p}<0,05$. Los resultados se presentan como medianas, rangos y porcentajes.

\section{Resultados efecto de diferentes dosis de radiación gamma sobre CMSP}

Las CMSP fueron expuestas inicialmente a 150, 300, 450, 600 y 750 cGy de radiación y se hizo una valoración cualitativa de la presencia de daño en el ADN. No se observó diferencia en el daño inducido en el ADN entre las distintas dosis de radiación (datos no mostrados). Con base en esta observación y en un estudio previo realizado en el Laboratorio de Genética Humana de la Universidad de los Andes con rayos X (300cGy); (14) se escogió la dosis de 300 cGy de rayos gamma para realizar los experimentos con melatonina.

\section{Efecto de radiación gamma (300cGy) sobre las CMSP}

En las CMSP expuestas a 300cGy de radiación gamma, la longitud de los cometas alcanzó una mediana de 140,5 $\mu \mathrm{m}$. Este daño fue significativamente diferente (MannWhitney; $\mathrm{p}<0.0001$ ) al daño espontáneo presente en las CMSP control no irradiadas que fue sólo de 63,3 $\mu \mathrm{m}$ (Tabla 1, Figura 1).

\section{Efecto de la melatonina sobre las CMSP}

La melatonina no tuvo ningún efecto protector sobre el daño espontáneo del ADN en células no irradiadas. La longitud de los cometas en las CMSP no irradiadas y no pre-tratadas con melatonina fue de $63,3 \mu \mathrm{m}$ y no resultó significativamente diferente (Mann-Whitney; $\mathrm{p}>0.05$ ) del daño en las células no irradiadas tratadas con las diferentes dosis de la hormona; en efecto, en presencia de $1 \times 10^{-7}$, $1 \times 10^{-6}$ y $1 \times 10^{-5} \mathrm{M}$ de melatonina, las medianas de la longitud de los cometas fueron de 61,$1 ; 59,5$ y $61,1 \mu \mathrm{m}$ respectivamente (Tabla 1, Figura 1) 


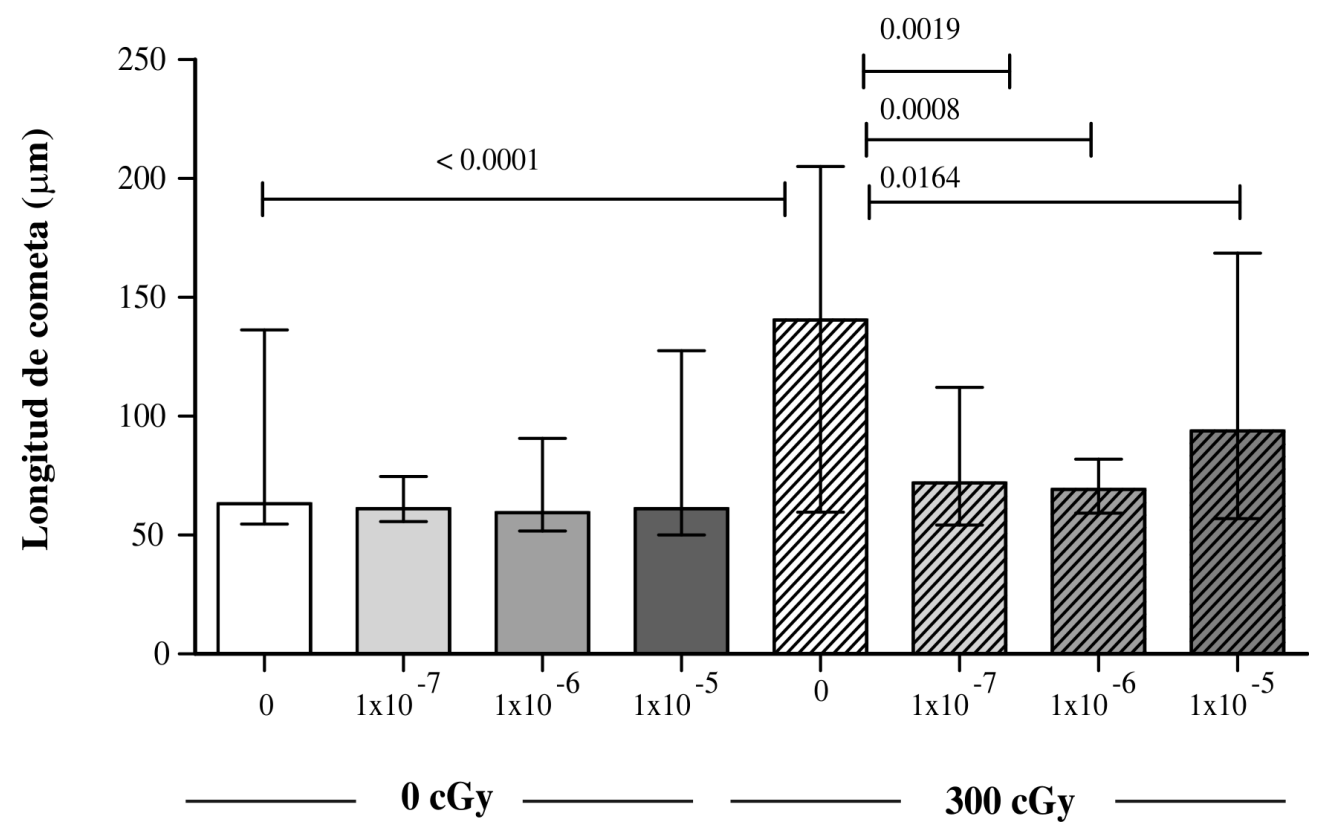

Figura 1. Efecto de la melatonina sobre CMSP sometidas a radiación gamma (300 cGy). Las CMSP de voluntarios sanos fueron incubadas con diferentes dosis de melatonina durante 10 minutos antes de exponerlas a 300cGy de radiación en un acelerador de partículas $\mathrm{Co}^{60}$ El daño en el ADN se evaluó mediante el ensayo del cometa. Las barras corresponden a la mediana y el rango de 7-18 láminas analizadas (en cada lámina se midió la longitud del cometa de 25 células). Los números indican el valor $\mathrm{p}$ de las comparaciones entre dos grupos mediante el test de Mann-Whitney.

Tabla 1. Efecto de la melatonina sobre CMSP humanas sometidas a radiación gamma (300cGy)

\begin{tabular}{|c|c|c|c|c|c|c|c|c|}
\hline \multirow{2}{*}{$\begin{array}{l}\text { Melatonina (M) } \\
\text { Radiación (cGy) }\end{array}$} & \multicolumn{2}{|c|}{0} & \multicolumn{2}{|c|}{$1 \times 10^{-7}$} & \multicolumn{2}{|c|}{$1 \times 10^{-6}$} & \multicolumn{2}{|c|}{$1 \times 10^{-5}$} \\
\hline & 0 & 300 & 0 & 300 & 0 & 300 & 0 & 300 \\
\hline \multicolumn{9}{|c|}{ Daño en ADN (mm de longitud de cometa) } \\
\hline Láminas (n) & 18 & 17 & 9 & 7 & 8 & 7 & 10 & 11 \\
\hline Células/lámina & 450 & 425 & 225 & 175 & 200 & 175 & 250 & 275 \\
\hline Mediana & 63,3 & 140,5 & 61,1 & 72,1 & 59,5 & 69,3 & 61,1 & 93,9 \\
\hline Mínimo & 54,7 & 59,7 & 55,6 & 54,3 & 51,8 & 59,3 & 50,2 & 57 \\
\hline Máximo & 136 & 205 & 74,8 & 112,2 & 90,7 & 82,1 & 127,7 & 168,7 \\
\hline
\end{tabular}

\section{Efecto de la melatonina sobre CMSP expuestas a radiación gamma (300 cGy)}

El daño en el ADN fue significativamente menor en las CMSP irradiadas pre-tratadas con la hormona comparado con el daño en las CMSP irradiadas en ausencia de melatonina. La mediana de la longitud de los cometas en las CMSP irradiadas fue de $140,5 \mu \mathrm{m}$ y en las pre-tratadas con melatonina $1 \times 10^{-7}, 1 \times 10^{-6}$, y $1 \times 10^{-5} \mathrm{M}$ fue de $72,1 \mu \mathrm{m}$ (Mann-Whitney; $\mathrm{p}=0,0019$ ); 69,3 $\mu \mathrm{m}$ (Mann-Whitney; $\mathrm{p}=0.0008$ ) y 93,9 $\mu \mathrm{m}$ (Mann-Whitney; $\mathrm{p}=0,0164)$ respectivamente (Tabla 1, Figura 1). 
Efecto de la melatonina sobre la proporción de daño en el ADN en CMSP expuestas a radiación (300cGy): En las CMSP expuestas a radiación (300cGy) se observó una mayor frecuencia de células con daño tipo 3. Esta frecuencia disminuyó significativamente en presencia de dosis de la hormona de $1 \times 10^{-7}, 1 \times 10^{-6}$ y $1 \times 10^{-5} \mathrm{M}$ (Figura 2).

\section{Discusión}

En este trabajo se determinó la acción protectora de la melatonina sobre CMSP sometidas a radiación gamma; para ello se evaluó el daño en el ADN mediante el ensayo del cometa a pH alcalino. Se utilizó en líneas generales el protocolo propuesto por Singh (1988), excepto que el tratamiento con álcali a $\mathrm{pH}=13$ para desenrollar el $\mathrm{ADN}$ se realizó durante 30 minutos. Al tratar las CMSP con melatonina antes de la radiación, se observó que la hormona disminuía el daño en el ADN de las células medido como longitud de la cola del ADN y como porcentaje de células afectadas. El efecto protector fue evidente con dosis de $1 \times 10^{-5}, 1 \times 10^{-6}$ y $1 \times 10^{-7} \mathrm{M}$; concentraciones mayores que las fisiológicas que se encuentran en el rango de $4 \times 10^{-11} \mathrm{a}$ $2,60 \times 10^{-10} \mathrm{M}(7,15)$.
Teniendo en cuenta que el daño en el ADN es debido a los radicales libres generados por la radiación ionizante y que la melatonina tiene un poder antioxidante, se asume que el efecto protector de la hormona sobre el daño en el ADN, se debe a su habilidad de atrapar los radicales $\cdot \mathrm{OH}$, pero sería necesario realizar ensayos para la detección de estos radicales en células irradiadas en presencia y ausencia de melatonina, utilizando técnicas específicas como la incubación con hidroetidina y análisis por citometría de flujo.

En el presente trabajo se demostró que a concentraciones de $1 \times 10^{-7}, 1 \times 10^{-6}$ y $1 \times 10^{-5} \mathrm{M}$ de melatonina, el daño en el ADN de las células irradiadas disminuye. En trabajos previos se había observado que dosis de melatonina de 0,5 $2,0 \times 10^{-3} \mathrm{M}$ protegían a linfocitos de sangre periférica humana del daño ocasionado por $150 \mathrm{cGy}$, evaluado mediante el ensayo de micronúcleos $(16,17)$. De acuerdo con los resultados del presente trabajo, es evidente que la acción protectora de la melatonina sobre células irradiadas se extiende a dosis menores de $0,5 \times 10^{-3} \mathrm{M}$. En un trabajo reciente se observó mediante ensayos de micronúcleos y

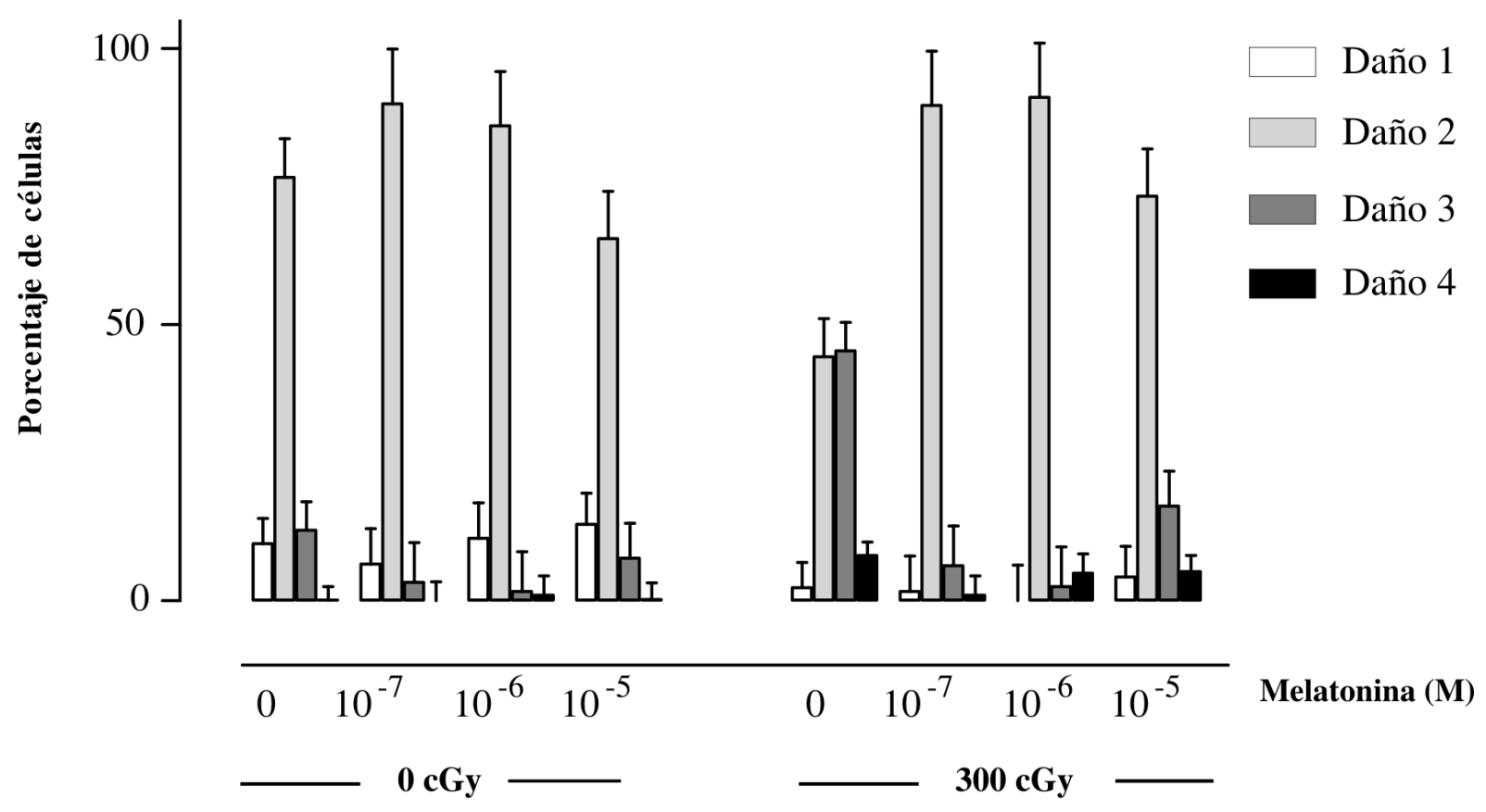

Tratamiento

Figura 2. Efecto de la melatonina sobre la extensión del daño al ADN en CMSP expuestas a radiación (300 cGy). Las CMSP de voluntarios sanos fueron incubadas con diferentes dosis de melatonina durante 10 minutos antes de exponerlas a 300 cGy de radiación en un acelerador de partículas $\mathrm{Co}^{60}$ El daño en el ADN se evaluó mediante el ensayo del cometa. El grado de la lesión al ADN se clasificó como tipo 1 ( $\leq 57 \mu \mathrm{m}), 2$ (58-114 $\mu \mathrm{m}), 3$ (115-228 $\mu \mathrm{m})$ ó 4 (>228 $\mu \mathrm{m})$. 
de intercambio de cromátides hermanas que la melatonina en concentración de $2 \mathrm{mM}$ protege a los linfocitos humanos del daño causado por dosis de radiación gamma de $2 \mathrm{~Gy}$ (18). Es importante señalar que en el presente trabajo aunque la dosis de radiación fue casi siete veces menor que la utilizada por Kopjar et al. (2006), la concentración radioprotectora de la melatonina fue alrededor de 4 órdenes de magnitud menor que la empleada en el trabajo citado. Esto puede estar relacionado con la alta sensibilidad del ensayo del cometa comparado con el de micronúcleos y el de intercambio de cromátides hermanas, en el cual aún a pequeñas dosis de radiación, los daños en el ADN pueden ser detectados. Los resultados de estos experimentos in vitro son similares a los observados en individuos que ingirieron $300 \mathrm{mg}$ de melatonina antes de que sus linfocitos fueran sometidos a radiación in vitro $(19,20)$.

\section{Conclusiones}

Los resultados de este estudio confirman el efecto radioprotector de la melatonina sobre CMSP irradiadas con rayos gamma y comprueban su acción incluso a dosis de 300 cGy con concentraciones de la hormona menores a las descritas en trabajos previos. Esta cualidad de la melatonina puede ser fácilmente monitoreado con una metodología sensible, sencilla y rápida como el ensayo del cometa.

\section{Agradecimientos}

Al Departamento de Radiología del Instituto Nacional de Cancerología, Bogotá.

\section{Financiación}

Este trabajo fue financiado con recursos del laboratorio de Inmunobiología y Biología Celular del departamento de Microbiología de la Pontificia Universidad Javeriana y del laboratorio de Genética Humana del Departamento de Biología de la Universidad de Los Andes.

\section{Conflicto de intereses}

Los autores afirman no tener conflictos de intereses.

\section{Referencias}

1. Cadet J, Douki T, Ravanat JL. Oxidatively generated damage to the guanine moiety of DNA: mechanistic aspects and formation in cells, Accounts of Chemical Research 2008; 41 (8): 1075-1083.
2. Maynard S, Schurman SH, Harboe C, de Souza-Pinto NC, Bohr VA. Base excision repair of oxidative DNA damage and association with cancer and aging, Carcinogenesis 2009; 30 (1): 2-10.

3. Tubiana M, Introduction to Radiobiology, ed., Taylor and Francis Group, London 1990, 381 p.

4. Matsumoto H, Hamada N, Takahashi A, Kobayashi Y, Ohnishi T. Vanguards of paradigm shift in radiation biology: radiation-induced adaptive and bystander responses, Journal of Radiation Research 2007; 48 (2): 97-106.

5. Shirazi A, Ghobadi G, Ghazi-Khansari M. A radiobiological review on melatonin: a novel radioprotector, Journal of Radiation Research 2007; 48 (4): 263272.

6. Arendt J, Symons AM, Wirz-Justice A, Wilkinson M. Radioimmunoassayable melatonin in various species [proceedings], Journal of Endocrinology 1978; 79 (2): 25P-26P.

7. Brzezinski A. Melatonin in humans, New England Journal of Medicine 1997; 336 (3): 186-195.

8. Tan DX, Manchester LC, Terron MP, Flores LJ, Reiter RJ. One molecule, many derivatives: a never-ending interaction of melatonin with reactive oxygen and nitrogen species?, Journal of Pineal Research 2007; 42 (1): 28-42.

9. Hardeland R, Balzer I, Poeggeler B, Fuhrberg B, Uria H, Behrmann G, Wolf R, Meyer TJ, Reiter RJ. On the primary functions of melatonin in evolution: mediation of photoperiodic signals in a unicell, photooxidation, and scavenging of free radicals, Journal of Pineal Research 1995; 18 (2): 104-111.

10. Hardeland R, Reiter RJ, Poeggeler B, Tan DX. The significance of the metabolism of the neurohormone melatonin: antioxidative protection and formation of bioactive substances, Neuroscience and Biobehavioral Reviews 1993; 17 (3): 347-357.

11. Karbownik M, Reiter RJ. Antioxidative effects of melatonin in protection against cellular damage caused by ionizing radiation, Proceedings of the Society for Experimental Biology and Medicine 2000; 225 (1): 9-22.

12. Tice RR, Agurell E, Anderson D, Burlinson B, Hartmann A, Kobayashi H, Miyamae Y, Rojas E, Ryu JC, Sasaki YF. Single cell gel/comet assay: 
guidelines for in vitro and in vivo genetic toxicology testing, Environmental and Molecular Mutagenesis 2000; 35 (3): 206-221.

13. Cemeli E, Baumgartner A, Anderson D. Antioxidants and the Comet assay, Mutation Research 2009; 681 (1): 51-67.

14. Restrepo HG, Sicard D, Torres MM. DNA damage and repair in cells of lead exposed people, American Journal of Industrial Medicine 2000; 38 (3): 330334.

15. Benloucif S, Burgess HJ, Klerman EB, Lewy AJ, Middleton B, Murphy PJ, Parry BL, Revell VL. Measuring melatonin in humans, Journal of Clinical Sleep Medicine 2008; 4 (1): 66-69.

16. Vijayalaxmi, Leal BZ, Deahl TS, Meltz ML. Variability in adaptive response to low dose radiation in human blood lymphocytes: consistent results from chromo- some aberrations and micronuclei, Mutation Research 1995; 348 (1): 45-50.

17. Vijayalaxmi, Reiter RJ, Meltz ML. Melatonin protects human blood lymphocytes from radiation-induced chromosome damage, Mutation Research 1995; 346 (1): 23-31.

18. Kopjar N, Miocic S, Ramic S, Milic M, Viculin T. Assessment of the radioprotective effects of amifostine and melatonin on human lymphocytes irradiated with gamma-rays in vitro, Arhiv Za Higijenu Rada $i$ Toksikologiju 2006; 57 (2): 155-163.

19. Vijayalaxmi, Reiter RJ, Herman TS, Meltz ML. Melatonin reduces gamma radiation-induced primary DNA damage in human blood lymphocytes, Mutation Research 1998; 397 (2): 203-208.

20. Vijayalaxmi, Reiter RJ, Meltz ML, Herman TS. Melatonin: possible mechanisms involved in its 'radioprotective' effect, Mutation Research 1998; 404 (1-2): 187-189. 